\title{
Development and Validation of the UPLC Method for the Simultaneous Assay of the Compounding Ointment Components
}

\author{
Lesia P. Savchenko ${ }^{1 *}$, Liudas Ivanauskas ${ }^{2}$, Victoriya A. Georgiyants ${ }^{3}$ \\ ${ }^{1}$ Department of Quality, Standardization and Certification of Medicines Institute of Pharmacy Professionals Qualification Improvement, National University \\ of Pharmacy, Kharkiv, Ukraine. \\ ${ }^{2}$ Department of Analytical and Toxicological Chemistry, Lithuanian University of Health Sciences, Kaunas, Lithuania. \\ ${ }^{3}$ Department of Pharmaceutical Chemistry, National University of Pharmacy, Kharkiv, Ukraine.
}

\section{ARTICLE INFO \\ Article history: \\ Received on: $11 / 02 / 2018$ \\ Accepted on: 28/03/2018 \\ Available online: 30/05/2018}

\section{Key words:}

Simultaneous determination, sulfanilamide, procaine hydrochloride, tetracycline hydrochloride, compounding ointment, UPLC.

ABSTRACT
Semi-solid compounding dosage forms always were popular in the treatment of dermatological diseases all over the
world. These medicines are often prepared using industrial production ointments. One of them is the tetracycline
hydrochloride ointment with the addition of procaine hydrochloride, sulfanilamide, and sulphur for external use. Since
the literature data contains a small amount of information on the methods of quantitative analysis of compounding
medicines, the aim of our study was the development of the chromatographic method for the ointment components
assay. During the research, HPLC method was developed for the simultaneous assay of studied ointment active
ingredients. The procedure was tested on the UPLC due to its advantages. Good separation of sulfanilamide $\left(\mathrm{t}_{\mathrm{R}}=\right.$
$0.53 \mathrm{~min})$, procaine hydrochloride $\left(\mathrm{t}_{\mathrm{R}}=2.76 \mathrm{~min}\right)$ and tetracycline hydrochloride $\left(\mathrm{t}_{\mathrm{R}}=6.50 \mathrm{~min}\right)$ was obtained. Total
uncertainty value of the method doesn't exceed its maximum. The study of the method linearity in the concentration
range from $2.34 \times 10^{-6} \mathrm{~g} / \mathrm{ml}$ to $3.00 \times 10^{-4} \mathrm{~g} / \mathrm{ml}$ for each component showed good results. Parameters of precision
and accuracy of the method meet the established criteria. The obtained RSD values were quite low and indicate good
reproducibility of the method. Thus the developed method can be used for the ointment analysis and its chemical
stability studies.

\section{INTRODUCTION}

Semi-solid dosage forms (SSDF) have always occupied a significant part in the entire volume of extemporal medicines production. Despite the rapidly developing market of finished medicines in foreign countries, extemporal dosage forms (EDF) have not lost their significance. Analysis of their assortment had shown that the most popular compounding preparations are used to treat different dermatological diseases (Masupye et al., 2015; Kristina et al., 2017; Buurma et al., 2003). Dermatological preparations hold the main part of EDF in Sweden, Palestine, the United States, the Netherlands (Kristina et al., 2017), Bulgaria and Greece (Dimitrov et al., 2015). They occupied the second place

\footnotetext{
*Corresponding Author

Lesia Savchenko, Department of Quality, Standardization and Certification of Medicines Institute of Pharmacy Professionals Qualification Improvement, National University of Pharmacy, Kharkiv, Ukraine.E-mail: savchenkolesia@gmail.com
}

in the tertiary hospital complex in the Limpopo Province, South Africa (Masupye et al., 2015). Indispensable are compounding ointments in the treatment of dermatological diseases in Spain (Sanchez-Regana et al., 2013) and in the Dutch community pharmacies (Buurma et al., 2003).

In Ukraine, SSDF occupies up to $10 \%$ of total volume of compounding medicines production. Most of them (up to 60\%) include ointments of industrial production (Korytnyuk et al., 2007).

The fundamental question in the possibility of further compounding medicines preparation is their compliance with modern quality requirements. The occurrence of unwanted or toxic side effects on the body arises due to the lack of standard protocols for their preparation, and the presence of a minimum amount of information on their stability and storage conditions (Masupye et al., 2015; Kristina et al., 2017; Buurma et al., 2003).

Requirements for the quality of compounding ointments in Ukraine contain general articles "Medicinal products" (State 
Pharmacopoeia of Ukraine, Vol. 1, 2015) and "Non-sterile drugs, prepared in pharmacies", as well as a private article "Semi-solid compounding medicines" (State Pharmacopoeia of Ukraine, Vol. 3, 2014) of the SPhU. In accordance with its requirements SSDF controlled by the following parameters: definition, total mass or volume, uniformity, assay. The storage conditions and the shelf life of the medicines should be justified by the results of the conducted scientific research or literature data.

To date, the literature contains a limited amount of information on quality control and stability estimation methods for compounding ointments. This problem causes the need for their development. Special difficulties, in this case, represent multicomponent dosage forms when the analysis in one sample by spectrophotometry or titration methods often is not possible due to the similar properties of active ingredients. Based on this, the aim of our research was to develop the method for simultaneous assay of the active ingredients of compounding ointment prepared using $3 \%$ tetracycline ointment of industrial production for external use with the addition of procaine hydrochloride, sulfanilamide, and sulphur for external use. This ointment is often found in pharmacy practice and used for the treatment of many dermatological diseases and the optimal combination of its components allows to expand the spectrum of tetracycline ointment action.

\section{MATERIALS AND METHODS}

Class A glassware, tetracycline hydrochloride substance (series 20131211, manufactured by Farmak, Ukraine), sulfanilamide substance (series 310416, manufactured by Jinan Jinda Pharmaceutical Chemistry Co., Ltd, China), procaine hydrochloride substance (series 140716, manufactured by Guanxi Shengtai Chemical Co., Ltd, China), tetracycline ointment 3\% (series 80615, manufactured by Nizhpharm, Russia) and extemporal ointment: sulfanilamide 1,0; procaine hydrochloride 0,5 ; sulphur for external use 0,5 , tetracycline ointment $3 \%-10,0$ were used for the work.

Methanol and acetonitrile were of HPLC-grade (Sigma Aldrich, USA). Trifluoroacetic acid (Sigma Aldrich, USA) was of analytical grade. Water was purified before use in a Milli-Q system (Millipore, Bedford, USA). Ultrasonic Cleaner Set (Wise Clean WUC-A06H) was used for the sample preparation. For the quantitative determination, the external standard method was used.

\section{HPLC}

The studies were conducted using HPLC Waters e 2695 Separation Module equipped with a PDA detector. The analytical column was ACE 5 C18 $(250 \times 4,6 \mathrm{~mm})$ with precolumn ACE 5 C18 $(10 \times 4,6 \mathrm{~mm})$.

The mobile phase A: $0,1 \%$ solution of trifluoroacetic acid in water; B: acetonitrile. The gradient elution ( $\mathrm{min} / \% \mathrm{~A})$ was as follows: $0 / 95 ; 20 / 50 ; 21 / 95$.

The flow rate of mobile phase was $1 \mathrm{ml} / \mathrm{min}$. Injection volume was $10 \mu \mathrm{l}$. Absorbance measurements were held on the range from 210 to $400 \mathrm{~nm}$. The column temperature was $25^{\circ} \mathrm{C}$. The sample tray temperature was set at $4^{\circ} \mathrm{C}$.

\section{UPLC}

UPLC Waters Acquity H equipped with column Acquity UPLC BEH C18 1,7 $\mu \mathrm{m}(2,1 \times 50 \mathrm{~mm})$ was used for the analysis.
The mobile phase A: $0,1 \%$ solution of trifluoroacetic acid; B: acetonitrile. The gradient elution $(\mathrm{min} / \% \mathrm{~A})$ was as follows: 0/98; 1/98; 5/50; 6/20; 7/10;8/98.

The flow rate of mobile phase was $0,5 \mathrm{ml} / \mathrm{min}$. Injection volume was $1 \mu \mathrm{l}$. Absorbance measurements were held on the range from 210 to $400 \mathrm{~nm}$. The column temperature was $25^{\circ} \mathrm{C}$, the sample tray temperature was $4^{\circ} \mathrm{C}$.

The wavelength for the sulfanilamide determination was $258 \mathrm{~nm}$, tetracycline hydrochloride $-270 \mathrm{~nm}$, procaine hydrochloride $-282 \mathrm{~nm}$.

Reference solution preparation. Standard solutions of each compound were prepared by dissolving $0.010 \mathrm{~g}$ of the compound in of methanol and dilution to the mark $10.0 \mathrm{ml}$ in the volumetric flask to obtain a final concentration of $1 \times 10^{-3}$ $\mathrm{g} / \mathrm{ml}$. A mix of standard solutions of tetracycline hydrochloride, sulfanilamide and procaine hydrochloride for the calibration was prepared by mixing $1.50 \mathrm{ml}$ of each standard solution and dilution to the mark $5.0 \mathrm{ml}$ in the volumetric flask with methanol to obtain a final concentration of $3 \times 10^{-4} \mathrm{~g} / \mathrm{ml}$ for each component.

Method for extraction of ointment components. $0.500 \mathrm{~g}$ of the ointment was weighed into a measuring beaker; $20 \mathrm{ml}$ of methanol was added and extracted for 10 minutes in a water bath with ultrasound at $30^{\circ} \mathrm{C}$. The methanol extract was transferred to the $100.0 \mathrm{ml}$ volumetric flask. The procedure was repeated three more times, adjusted to the mark $100.0 \mathrm{ml}$ with methanol. The solution was cooled and placed for 1 hour in a refrigerator for precipitation of ointment base components. The extract was filtered through a filter Q-MAX RR Syringe Filters (filter diameter $25 \mathrm{~mm}$, membrane 0,22 $\mu \mathrm{m}$ PTFE Hydrophobic). $2.00 \mathrm{ml}$ of final methanol extract was mixed with $2.00 \mathrm{ml}$ of methanol.

\section{RESULTS AND DISCUSSION}

\section{Method development}

For the analysis of tetracycline hydrochloride, SPhU suggests using the HPLC method with an isocratic regime and a mixture of 2-methyl-2-propanol, dipotassium hydrogen phosphate, tetrabutylamonium hydrogen sulfate and sodium edetate $(\mathrm{pH} 9.0)$ as the mobile phase (State Pharmacopoeia of Ukraine, Vol. 2, 2014). Procaine hydrochloride and sulfanilamide are determined by nitrogen in the amino group (State Pharmacopoeia of Ukraine, Vol. 2, 2014).

HPLC with UV-detectors the most commonly used for the determination of tetracycline hydrochloride residue in food. In this case, both isocratic and gradient elution is used. The combinations of mobile phases used for analysis are characterized by a wide variety (e.g., oxalic acid or oxalate buffers at acid $\mathrm{pH}$, citrate buffers and phosphate buffer, sodium acetate buffer, acetonitrile, methanol and their combinations, $0.1 \%$ formic acid in water and $0.1 \%$ formic acid in methanol) (Shama et al., 2016; Abbasi et al., 2011; Patyra et al., 2015; Roy and Gogoi, 2014; Taokaenchan and Sangsrichan, 2010; Singh et al., 2015).

The assay of tetracycline in single and multicomponent dosage forms was proposed to carry out using HPLC by isocratic elution with the mixture of acetonitrile and acetate buffer solution as the mobile phase after complexation with metals (Abdulghani et al., 2013), by gradient mode using 0,1\% phosphoric acid and acetonitrile (Hussien, 2014) or an acetonitrile/ammonium 
dihydrogen orthophosphate $(\mathrm{pH}$ 2.2) as a mobile phase (Pelia, 2012). For the determination of tetracycline impurity in semisolid medicinal forms, the HPLC method with isocratic elution and a mobile phase consisting of acetonitrile-methanol-80 $\mathrm{mM}$ dipotassium phosphate ( $\mathrm{pH}$ 7.5) was proposed (Giugiu, 2013).

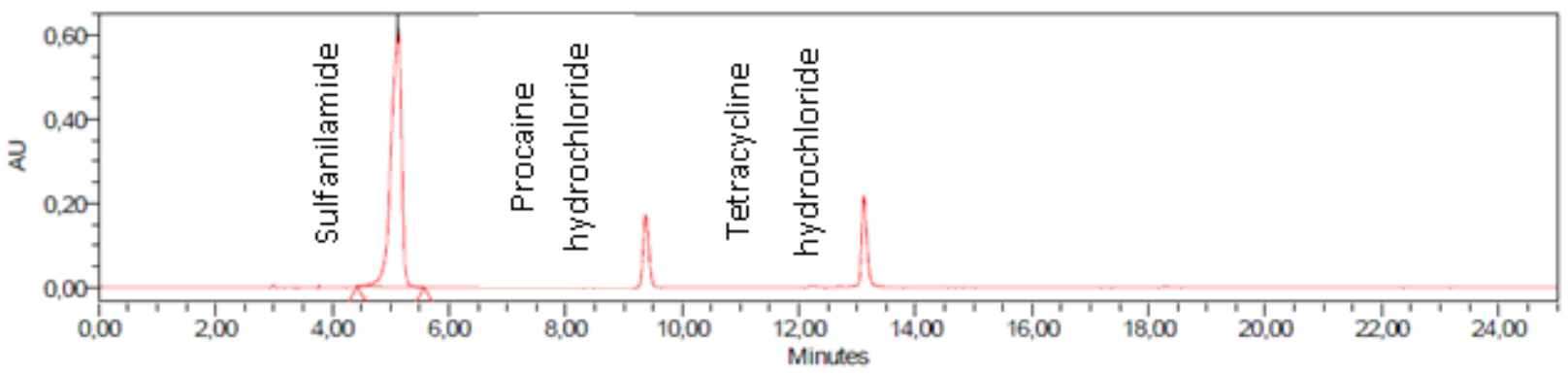

Fig. 1: Chromatogram of the ointment methanol extract HPLC analysis.

Table 1: The suitability parameters of the ointment assay procedure by HPLC.

\begin{tabular}{|c|c|c|c|}
\hline & Sulfanilamide & Procaine hydrochloride & Tetracycline hydrochloride \\
\hline Retention time & $\begin{array}{c}5.13 \\
\left(S_{r}=0.21 \%\right)\end{array}$ & $\begin{array}{c}9.37 \\
\left(S_{r}=0.068 \%\right)\end{array}$ & $\begin{array}{c}13.11 \\
\left(S_{r}=0.056 \%\right)\end{array}$ \\
\hline Area & $\begin{array}{c}8112024.5 \\
\left(S_{r}=0.67 \%\right)\end{array}$ & $\begin{array}{c}3734276.5 \\
\left(S_{r}=1.92 \%\right)\end{array}$ & $\begin{array}{c}1434771 \\
\left(S_{r}=0.52 \%\right)\end{array}$ \\
\hline Amount $\mathrm{mg} / \mathrm{ml}$ & $\begin{array}{c}0.2205 \\
\left(S_{r}=0.0067 \%\right)\end{array}$ & $\begin{array}{c}0.1099 \\
\left(S_{r}=1.92 \%\right)\end{array}$ & $\begin{array}{c}0.06425 \\
\left(S_{r}=0.068 \%\right)\end{array}$ \\
\hline Plate count & $4017.815(R S D=0.80 \%)$ & $\begin{array}{c}45504.034 \\
(R S D=2.50 \%)\end{array}$ & $\begin{array}{c}109774.33 \\
(R S D=0.063 \%)\end{array}$ \\
\hline
\end{tabular}

* Each number is the average result of four measurements.

HPLC method with gradient elution and $20 \mathrm{mM}$ ammonium acetate/methanol as a mobile phase was developed for the simultaneous determination of procainamide and sulfanilamide in human plasma (MacRitchie, 2011). For the assay of sulfanilamide by HPLC, $0.1 \%$ formic acid in water and $0.1 \%$ formic acid in acetonitrile ( $\mathrm{pH} 2.7$ ) most often use as a mobile phase with gradient elution (Lake and Kahler, 2012; Long and Henderson, 2012; Hug and Kallury, 2006). For the sulfanilamide residues assay in honey was proposed HPLC method with a gradient mode and a mobile phase $0.02 \mathrm{M} \mathrm{H}_{3} \mathrm{PO}_{4}$ (eluent $\mathrm{A}$ ) and methanol: acetonitrile (1:1) (eluent B) (Szczesna, 2009).

Based on the analysis of conducted research and the properties of the substances, the study was carried out using gradient elution. The mixture of $0.1 \%$ solution of trifluoroacetic acid and acetonitrile was chosen as a mobile phase.

The mixed standard solution with concentration $3 \times$ $10^{-4} \mathrm{~g} / \mathrm{ml}$ of each component was prepared for simultaneously calibrating and calculating of substances content in ointment which will significantly reduce the analysis time. During the research was found that at a sample temperature of $25^{\circ} \mathrm{C}$, the mixture remains stable for only an hour, so it was recommended that the sample temperature for research must be $4^{\circ} \mathrm{C}$. Obtained results indicated a good separation of substances and allow recommend this method for the quantitative determination of the ointment components. After preparation of the ointment methanol extract, its analysis was carried out by the developed method. Results (Figure 1) indicate a good separation of substances within 15 minutes.

To establish the possibility of this technique using for the quantitative analysis of the ointment, the acceptance, and the system suitability criteria were studied. The parameters characterizing the possibility of components separation plate count, symmetry factor and resolution were calculated using the software. Repeatability of the response was expressed as an estimated percentage relative standard deviation $\left(S_{r}, \%\right)$ for the parameters of retention time, area, height and amount. It was evaluated by four consecutive series of injections of ointment methanol extract.

Maximum allowable value for four parallel injections is $1.92 \%$. The obtained data indicate the possibility of this technique using for assay of ointment active ingredients (Table 1).

The most promising method of analysis today is UPLC due to the particle chemistry design, system optimization, detector design, data processing, and control. This significantly increases substances resolution that defines as a peak shape, method sensitivity, and rate. UPLC allows conducting more difficult separations of complex mixtures, a significant reduction in solvent use and time of the analysis (Swartz, 2005).

Therefore, our further goal was testing the proposed analysis technique on the UPLC. The resulting chromatogram of the reference solution analysis (Figure 2) indicates a good separation of substances within four minutes and allows recommend this method for analysis of the studied ointment.

\section{Method validation}

To prove the possibility of this method using for the assay of the ointment components, its validation was carried out according to the requirements of the articles 5.3.N.2. "Validation of analytical methods and tests" and 2.2.46. "Chromatographic separation techniques" of the SPhU (State Pharmacopoeia of 
Ukraine, Vol. 1, 2015) and EurPh (European Pharmacopoeia, 2013). We used the concentration of $6.25 \times 10^{-5} \mathrm{~g} / \mathrm{ml}$ for tetracycline hydrochloride, $1.04 \times 10^{-4} \mathrm{~g} / \mathrm{ml}$ for procaine hydrochloride and $2.08 \times 10^{-4} \mathrm{~g} / \mathrm{ml}$ for sulfanilamide for the ointment analysis.

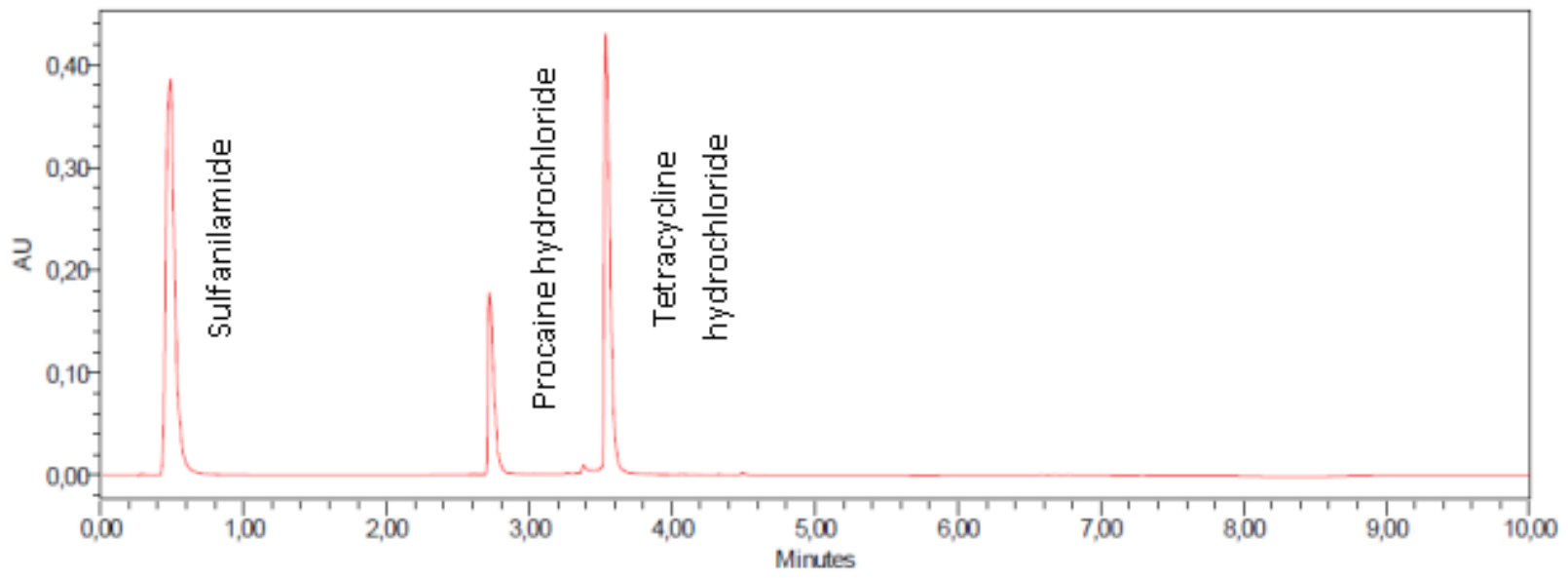

Fig. 2: Chromatogram of the reference solution UPLC analysis.

Table 2: Results of the linearity study of the UPLC method.

\begin{tabular}{ccc}
\hline Component & Linear equation & $\mathbf{r}^{2}$ \\
\hline Sulfanilamide & $\mathrm{y}=0.97 \mathrm{x}+2.15$ & 0.999957 \\
Procaine hydrochloride & $\mathrm{y}=0.98 \mathrm{x}+0.52$ & 0.999964 \\
Tetracycline hydrochloride & $\mathrm{y}=0.98 \mathrm{x}+0.52$ & 0.999945 \\
\hline
\end{tabular}

The maximum permissible uncertainty of the analysis results was calculated taking into account the allowable deviation in the components quantitative content in the compounding ointments according to the $\mathrm{SPhU}$ requirements $( \pm 10 \%): \max \Delta_{A s}=10 \times 0.32=3.2 \%$. During the uncertainty of sample preparation calculating $\left(\Delta_{S P_{r}}\right)$, all weighing and dilution preparation stages of the reference and the test solutions were taken into account.

The total uncertainty of sample preparation is $\Delta_{S P, r}=$ $1.63 \%$. It slightly exceeds the recommended framework (the relation $\Delta_{S P} \leq 0.32 \times \Delta_{A s}=1.024 \%$ is not satisfied). Thus, the requirements for the uncertainty of the final analytical operation are increased $\left(\Delta_{F A O, r}\right)$. Its calculation was performed using the combined standard deviation for each substance $\left(\Delta_{F A O, r}=0.64 \%\right)$.

The total uncertainty of the analysis will be: $\sqrt{ }$

$\Delta_{A S, r}=\sqrt{\Delta_{S P, r}^{2}+\Delta_{F A O, r}^{2}}=\sqrt{1.63^{2}+0.64^{2}}=1.75 \%$.

Its value does not exceed max $\Delta_{A s}$. It testifies that the method will give correct results during the ointment analysis in other laboratories.

In addition, the system suitability parameters were determined (Table 2). Repeatability of the method $\left(S_{r}\right)$ was calculated. Due to the requirements of the SPhU and EurPh for the components content deviation in the finished drug $\pm 10 \%$, its maximum allowable value for four parallel injections is $1.92 \%$. Obtained results (Table 2 ) indicate the conformity of the reproducibility results since the calculated values of $S_{r}$ for all components don't exceed $1.00 \%$. The peak separation coefficient is much larger than one, which indicates the reliability of the analysis.

Table 3: The suitability parameters of the ointment assay procedure by UPLC.

\begin{tabular}{|c|c|c|c|}
\hline & Sulfanilamide & Procaine hydrochloride & Tetracycline hydrochloride \\
\hline Retention time & $\begin{aligned} & 0.53 \\
\left(S_{r}=\right. & 0.0057 \%)\end{aligned}$ & $\begin{array}{c}2.76 \\
\left(S_{r}=0.24 \%\right)\end{array}$ & $\begin{array}{c}3.50 \\
\left(S_{r}=0.12 \%\right)\end{array}$ \\
\hline Area & $\begin{array}{c}1554288.5 \\
\left(S_{r}=0.33 \%\right)\end{array}$ & $\begin{array}{c}665523.75 \\
\left(S_{r}=0.26 \%\right)\end{array}$ & $\begin{array}{c}285852.3 \\
\left(S_{r}=0.37 \%\right)\end{array}$ \\
\hline Amount, mg/ml & $\begin{array}{c}0.2245 \\
\left(S_{r}=0.83 \%\right)\end{array}$ & $\begin{array}{c}0.1085 \\
\left(S_{r}=0.26 \%\right)\end{array}$ & $\begin{array}{c}0.06661 \\
\left(S_{r}=0.37 \%\right)\end{array}$ \\
\hline Plate count & $304.93(R S D=0.82 \%)$ & $\begin{array}{c}20532.93 \\
(R S D=2.05 \%)\end{array}$ & $\begin{array}{c}35942.38 \\
(R S D=1.33 \%)\end{array}$ \\
\hline Symmetry factor $\left(A_{s}\right)$ & $\begin{array}{c}1.41 \\
(R S D=0.62 \%)\end{array}$ & $\begin{array}{c}2.55 \\
(R S D=0.15 \%)\end{array}$ & $\begin{array}{c}2.55 \\
(R S D=0.20 \%)\end{array}$ \\
\hline Resolution & & $\begin{array}{c}22.46 \\
(R S D=0.41 \%)\end{array}$ & $\begin{array}{c}9.83 \\
(R S D=0.32 \%)\end{array}$ \\
\hline
\end{tabular}

Method linearity was evaluated by the construction of calibration curve in the range from $2.344 \times 10^{-6} \mathrm{~g} / \mathrm{ml}$ to $3 \times 10^{-4}$ $\mathrm{g} / \mathrm{ml}$ for each component at eight points with triplicate analysis
(Table 3). Results show that the response was linear and correlated with the amount of compounds mix solution injected as indicated by the value of the correlation coefficient $\left(\mathrm{r}^{2}\right)$. 
During the analysis, the accuracy and the precision of the method were determined (Table 4). Quantitation was made based on the linear calibration curves between the concentrations and peak area of standard solution. The resulting values do not exceed the allowable criteria.

Table 4: Results of the precision and accuracy study of UPLC method for the ointment assay.

\begin{tabular}{|c|c|c|c|}
\hline \multirow{2}{*}{ Validation characteristics } & \multicolumn{3}{|c|}{ The obtained value } \\
\hline & Sulfanilamide & Procaine hydrochloride & Tetracycline hydrochloride \\
\hline $\bar{Z}$ & 100.11 & 99.52 & 99.08 \\
\hline$S_{Z}$ & 0.76 & 0.37 & 0.38 \\
\hline \multirow[t]{2}{*}{$\Delta_{Z}$} & 1.32 & 0.66 & 0.66 \\
\hline & \multicolumn{2}{|c|}{ Criterion of one-sided confidence interval $\Delta_{Z} \leq \Delta_{A s}\left(\Delta_{Z} \leq 3.2\right)$} & \\
\hline \multirow[t]{4}{*}{$\delta$} & 0.11 & 0.48 & 0.92 \\
\hline & \multicolumn{2}{|c|}{ Criterion of statistical insignificance $\delta, \% \leq \Delta Z / \sqrt{ } n$} & \\
\hline & 0.33 & 0.16 & 0.17 \\
\hline & \multicolumn{2}{|c|}{ Criterion of practical insignificance $\delta, \% \leq 0.32 \times \Delta A s=1.024$} & \\
\hline
\end{tabular}

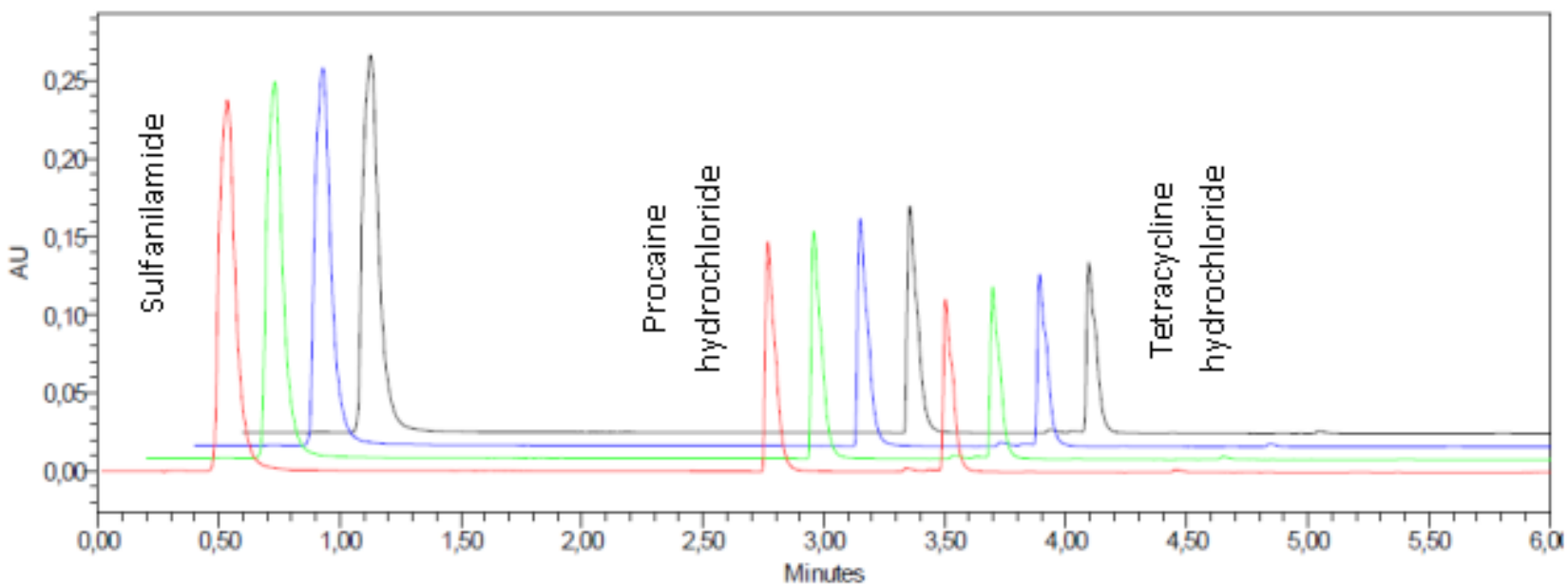

Fig. 3: Two-dimensional chromatogram of the ointment methanol extracts UPLC analysis.

Table 5: Results of method repeatability estimation.

\begin{tabular}{|c|c|c|c|c|}
\hline Compound & $\begin{array}{c}\text { Nominal } \\
\text { quantity, g }\end{array}$ & $\begin{array}{c}\text { Found } \\
\text { amount, g }\end{array}$ & $\begin{array}{c}\text { Recovery } \\
\text { percentage, \% }\end{array}$ & $\begin{array}{c}\text { Average } \\
\text { recovery, \% }\end{array}$ \\
\hline \multirow{5}{*}{$\begin{array}{l}\text { Sulfanil- } \\
\text { amide }\end{array}$} & \multirow{5}{*}{1.0000} & 1.0752 & 107.52 & \multirow{5}{*}{107.76} \\
\hline & & 1.0757 & 107.57 & \\
\hline & & 1.0829 & 108.29 & \\
\hline & & 1.0766 & 107.66 & \\
\hline & & & $\mathrm{RSD}, \%=0.33$ & \\
\hline \multirow{5}{*}{$\begin{array}{l}\text { Procaine } \\
\text { hydrochlo- } \\
\text { ride }\end{array}$} & \multirow{5}{*}{0.5000} & 0.5227 & 104.54 & \multirow{4}{*}{104.14} \\
\hline & & 0.5203 & 104.06 & \\
\hline & & 0.5194 & 103.88 & \\
\hline & & 0.5203 & 104.06 & \\
\hline & & & $\mathrm{RSD}, \%=0.27$ & \multirow{6}{*}{106.57} \\
\hline \multirow{5}{*}{$\begin{array}{l}\text { Tetracycline } \\
\text { hydrochlo- } \\
\text { ride }\end{array}$} & \multirow{5}{*}{0.3000} & 0.3215 & 107.17 & \\
\hline & & 0.3190 & 106.33 & \\
\hline & & 0.3191 & 106.37 & \\
\hline & & 0.3192 & 106.40 & \\
\hline & & & $\mathrm{RSD}, \%=0.38$ & \\
\hline
\end{tabular}

The reproducibility of the method was evaluated by four consecutive injections of the test ointment methanol extract
(Figure 3). The quantity of each component was evaluated and compared with the prescribed amount for the repeatability estimation of the method (Table 5). The obtained RSD values indicate good reproducibility of the results. It was determined from the results of the ointment test solution analysis. For the additional recovery study was evaluated three different concentrations of each substance on the LOQ studies (Table 6, Figure 4). They were chosen based on the test solution concentration of each substance. The results obtained indicate good recovery of the method.

For each substance limit of detection (LOD) and limit of quantification (LOQ) were calculated. For the sulfanilamide, LOD was $0.35 \mathrm{mg} / \mathrm{ml}$ and LOQ was $1.05 \mathrm{mg} / \mathrm{ml}$; for the procaine hydrochloride LOD was $0.047 \mathrm{mg} / \mathrm{ml}$ and LOQ was $0.14 \mathrm{mg} /$ $\mathrm{ml}$; for the tetracycline hydrochloride LOD was $0.28 \mathrm{mg} / \mathrm{ml}$ and LOQ was $0.86 \mathrm{mg} / \mathrm{ml}$. All values demonstrate that the method characterized by sufficient sensitivity to determine all components quantitative content.

To test the specificity of the assay procedure, the ointment base was prepared without adding sulfanilamide, procaine hydrochloride and tetracycline hydrochloride (placebo solution). The base was prepared using wool fat anhydrous and white soft 
paraffin substances in a ratio of $4: 6$, with ceresin adding $(20 \%$ of the total weight of the mixture of petrolatum and lanolin). On the obtained chromatogram (Figure 5) clearly seen the absence of peaks in the places of sulfanilamide, procaine hydrochloride, and tetracycline hydrochloride detection. It testifies high specificity of the UPLC method for ointment analysis and the possibility of its use for chemical stability analysis of the ointment.

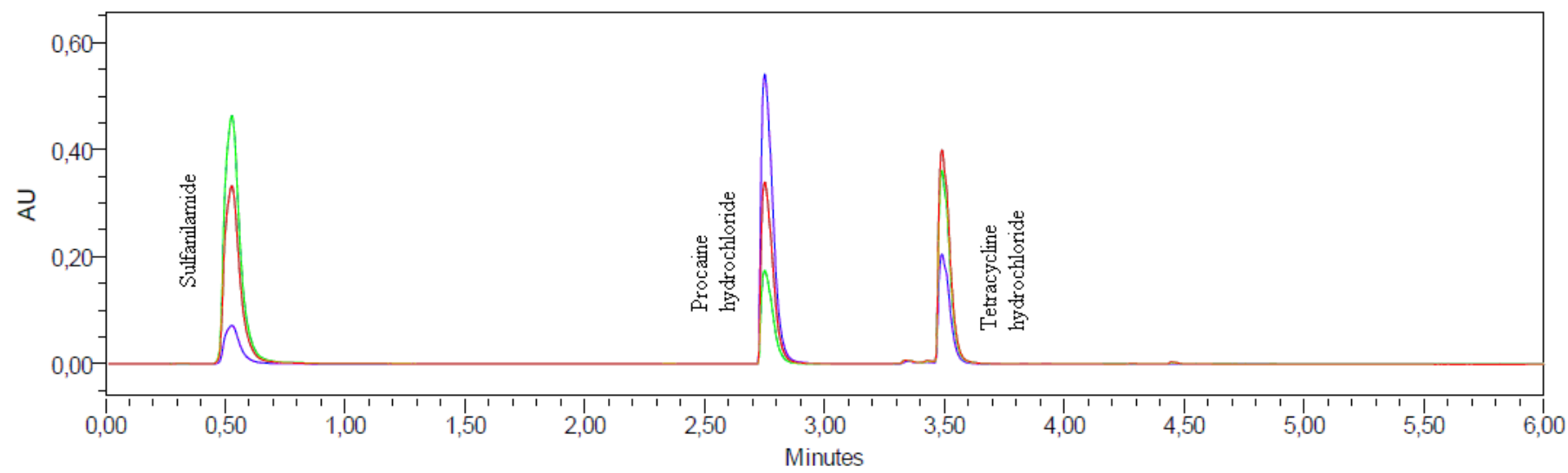

Fig. 4: Chromatogram of the standard solutions analysis by UPLC for the recovery study.

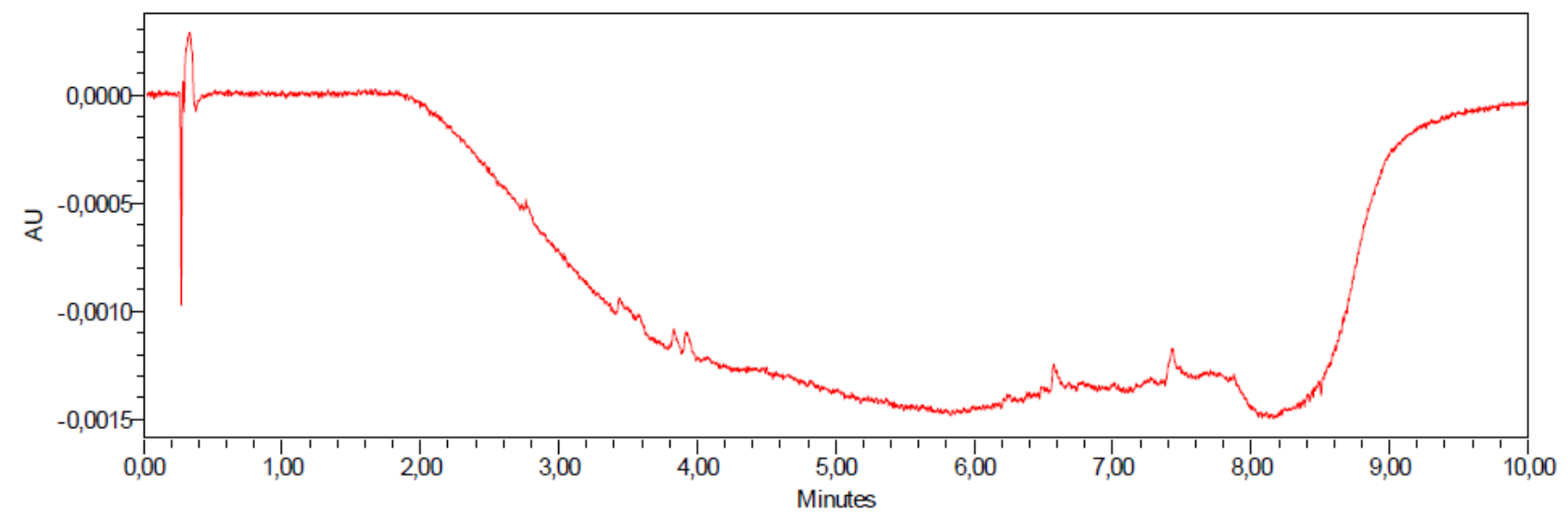

Fig. 5: Chromatogram of the placebo solution analysis by UPLC.

Table 6: The recovery study of the method.

\begin{tabular}{lccc}
\hline $\begin{array}{c}\text { Actual analyte } \\
\text { concentration, g/ml }\end{array}$ & $\begin{array}{c}\text { Founded analyte } \\
\text { concentration, g/ml }\end{array}$ & $\begin{array}{c}\text { Recovery } \\
\text { percentage, } \%\end{array}$ & RSD, \% \\
\hline $7.50 \times 10^{-5}$ & Sulfanilamide & & \\
$1.50 \times 10^{-4}$ & $1.32 \times 10^{-5}$ & 97.60 & 0.12 \\
$3.00 \times 10^{-4}$ & $2.93 \times 10^{-4}$ & 96.51 & 0.18 \\
& Procaine hydrochloride & 97.64 & 0.19 \\
$7.50 \times 10^{-5}$ & $7.38 \times 10^{-5}$ & 98.38 & 0.097 \\
$1.50 \times 10^{-4}$ & $1.46 \times 10^{-4}$ & 97.45 & 0.24 \\
$3.00 \times 10^{-4}$ & $2.95 \times 10^{-4}$ & 98.48 & 0.20 \\
& Tetracycline hydrochloride & \\
$3.75 \times 10^{-5}$ & $3.70 \times 10^{-5}$ & 98.76 & 0.74 \\
$7.50 \times 10^{-5}$ & $7.45 \times 10^{-5}$ & 99.37 & 2.02 \\
$1.50 \times 10^{-4}$ & $1,46 \times 10^{-4}$ & 97.31 & 0.076 \\
\hline
\end{tabular}

\section{CONCLUSIONS}

1. HPLC method for the simultaneous determination of sulfanilamide, procaine hydrochloride and tetracycline hydrochloride in compounding ointment was developed.

2. The developed method was tested on UPLC. The method was validated to prove the possibility of its using in the ointment analysis. The study of the system suitability parameters showed the possibility of this method using in the ointment analysis. The results of the validation parameters studying indicate the good parameters of method linearity, its high specificity, reproducibility, and accuracy.

3. The obtained results allow recommending the developed method for the ointment chemical stability analysis.

\section{REFERENCES}

Abbasi MM, Babaei H, Ansarin M, Nourdadgar A, Nemati M. Simultaneous determination of tetracyclines residues in bovine milk samples by solid-phase extraction and HPLC-FL method. APB. 2011; $1(1): 34-39$. 
Abdulghani AJ, Jasim HH, Hassan AS. Determination of tetracycline in pharmaceutical preparation by molecular and atomic absorption spectrophotometry and high performance liquid chromatography via complex formation with $\mathrm{Au}$ (III) and $\mathrm{Hg}$ (II) ions in solutions. Int J Anal Chem. 2013; ID 305124:11 p.

Buurma H, De Smet AGM Peter, Van den Hoff OP, Sysling H, Storimans M, Egberts CG. Frequency, nature and determinants of pharmacy compounded medicines in Dutch community pharmacies. Pharm World Sci. 2003; 25(6):280-287.

Dimitrov M, Petkova V, Husain Sh, Lambov N, Kourtidou L. Extemporaneous dispensing - comparative analysis between Greece and Bulgaria. WJPPS. 2015; 4(03):01-09.

European Pharmacopoeia. 2013. Strasbourg: European Directorate for the Quality of Medicines \& HealthCare of the Council of Europe, 8-th ed., Vol. 1, 1456 p.

Giugiu V. Simultaneous determination of related substances of oxytetracycline in pharmaceutical semi solid form by Hight Performance Liquid Chromatography. Vet Drug. 2013; 7(1):67-73.

Hug S, Kallury K. 2006. Extraction and analysis of sulfonamides from honey by LC/MS/MS using strata ${ }^{\mathrm{TM}} \mathrm{X}-\mathrm{C}$ polymeric SPE sorbent and gemini ${ }^{\mathrm{TM}} \mathrm{C} 18$ HPLC column Phenomenex Inc. CA, USA, 2 p.

Hussien EM. Development and validation of an HPLC method for tetracycline-related USP monographs. Biomed Chromatogr. 2014; 28(9):1278-1283

Korytnyuk RS, Vlasenko II, Rudenko VV. Ways of improvement of drug manufacturing in conditions of drugstores. Pharm review. 2007; $1: 44-48$.

Kristina SA, Wiedyaningsih C, Widyakusuma NN, Aditama H. Extemporaneous compounding practice by pharmacists: a systematic review. Int J Pharm Pharm Sci. 2017; 9(2):42-46.

Lake R, Kahler T. 2012. Increase data quality for sulfonamide residue analysis by HPLC and UPLC using unique biphenyl column selectivity. Food safety applications, USA: RESTEK, 3 p.

Long WJ, Henderson JW. 2012. Analysis of sulfa drugs on Eclipse Plus C 18. Application brief, USA: Agilent technologies, 2 p.

MacRitchie E. 2011. HPLC-UV Method for the determination of procainamide from human plasma using SOLA CX. UK: Thermo Fisher Scientific, 2 p.

Masupye EM, Suleman F, Govender T. Investigation extemporaneous compounding practices in the Polokwane tertiary hospital pharmacies in South Africa - a pilot study. Afr J Pharm Pharmacol. 2015; 9(48):1099-1105.

Patyra E, Kowalczyk E, Grelik A, Przenioslo-Siwczynska M, Kwiatek K. Screening method for the determination of tetracyclines and fluoroquinolones in animal drinking water by liquid chromatography with diode array detector. Pol J Vet Sci. 2015; 18(2):283-289.

Pelia S. 2012. Pharmaceutical Applications Notebook. Antibiotics. New HPLC \& UHPLC assay methods for tetracycline hydrochloride and 4-epianhydrotetracycline hydrochloride impurity in tetracycline drug products. Thermo scientific: Application note 288, p. 119125.

Roy DC, Gogoi R. HPLC and spectrophotometric analysis of tetracycline residues in marketed pork of Assam. TNJVAS. 2014; 43(2):98103.

Sanchez-Regana M, Llambi-Mateos F, Salleras-Redonnet M, Iglesias Sancho M, Collgros Totosaus H, Umbert-Millet P. Compounding as a current therapeutic option in dermatology. Actas Dermosifiliogr. 2013; 104(9):738-756.

Shama SA, El Sharkawy S, Mahmoud AH, Hassan HM, Nassar SH. Validation of modified HPLC method for determination of oxytetracycline, tetracycline and doxycycline in chicken meat and liver. $\mathrm{N}$ Y Sci J. 2016; 9(5):68-74.

Singh SP, Pundhir A, Ghosh S. Validation of an analytical methodology for determination of tetracyclines residues in honey by UPLC-MS/MS detection. IJNPR. 2015; 6(4):293-298.

State Pharmacopoeia of Ukraine: at 3 volumes. 2014. Kharkiv: State enterprise "Ukrainian scientific pharmacopoeial center of medicines quality", 2-nd ed., Vol. 2, 724 p.

State Pharmacopoeia of Ukraine: at 3 volumes. 2014. Kharkiv: State enterprise "Ukrainian scientific pharmacopoeial center of medicines quality", 2-nd ed., Vol. 3, 732 p.

State Pharmacopoeia of Ukraine: at 3 volumes. 2015. Kharkiv: State enterprise "Ukrainian scientific pharmacopoeial center of medicines quality", 2-nd ed., Vol. 1, 1128 p.

Swartz ME. UPLC ${ }^{\mathrm{TM}}$ : An Introduction and Review. J Liq Chrom Rel Technol. 2005; 28:1253-1263.

Szczesna T, Rybak-Chmielewska H, Was E, Pohorecka K. Study on sulfonamide residues in honey. JAS. 2009; 53(2):39-47.

Taokaenchan N, Sangsrichan S. HPLC-fluorescence detection method for quantitative determination of tetracycline antibiotic residues in honey. NU Int J Sci. 2010; 6(2):147-155.

How to cite this article:

Savchenko LP, Ivanauskas L, Georgiyants VA. Development and Validation of the UPLC Method for the Simultaneous Assay of the Compounding Ointment Components. J App Pharm Sci, 2018; 8(05): 061-067. 